\title{
Cardiopulmonary exercise testing following hay exposure challenge in farmer's lung
}

\author{
M. Schwaiblmair*, T. Beinert**, C. Vogelmeier*, G. Fruhmann*
}

Cardiopulmonary exercise testing following hay exposure challenge in farmer's lung. M. Schwaiblmair, T. Beinert, C. Vogelmeier, G. Fruhmann. (C) ERS Journals Ltd 1997. ABSTRACT: In patients experiencing an acute episode of hypersensitivity pneumonitis (HP), the alveoli and interstitium show a marked inflammation. The effects of this infiltration with effector cells on gas exchange and the cardiopulmonary system are not well characterized, and there are no data regarding cardiopulmonary exercise testing during hypersensitivity pneumonitis. The aim of this study was to gain new insights into the pathophysiology of acute farmer's lung using cardiopulmonary exercise testing. Cardiopulmonary exercise testing was performed in patients who had farmer's lung $(\mathrm{n}=21)$ before and $\mathbf{4} \mathrm{h}$ after a standardized exposure with mouldy hay. Farmers who were asymptomatic for this condition $(n=15)$ served as controls.

At baseline, patients who had farmer's lung had a decreased breathing reserve and a greater alveolar to arterial oxygen difference. Following exposure, all of these patients developed hypersensitivity pneumonitis. Compared to the asymptomatic farmers, they showed an increase of alveolar to arterial oxygen difference and functional dead space ventilation during exercise and a reduction of the breathing reserve. In addition, $40 \%$ of the asymptomatic farmers demonstrated a pathological increase of the alveolar to arterial oxygen difference during exercise following exposure.

In conclusion, our data signify that acute hypersensitivity pneumonitis induces significant changes in pulmonary gas exchange during exercise. Cardiopulmonary exercise testing may help to identify individuals with possible subclinical farmer's lung disease.

Eur Respir J 1997; 10: 2360-2365.

Acute episodes of farmer's lung, caused by the inhalation of particles of mouldy hay, including thermophilic actinomycetes and spores of Aspergillus species $[1,2]$, iis the most common form of hypersensitivity pneumonitis [3]. The diagnosis of farmer's lung is based mainly on clinical history, radiological evaluation, pulmonary function testing and serum antibodies [4]. However, up to now, little has been known about gas exchange and exercise capacity during the acute phase of hypersensitivity pneumonitis [5, 6]. In general, exercise testing provides information to the clinician that exceeds resting measurements [7, 8]. Furthermore, cardiopulmonary exercise testing allows objective measurement of maximum work capacity and differentiation between cardiac and ventilatory limitation. This is important, because circulatory impairment is often an unrecognized and dominant factor in exercise limitation of patients with interstitial lung disease [9].

It was the aim of this study to further evaluate the pathophysiology of acute farmer's lung using cardiopulmonary exercise testing. To achieve that goal, patients with farmer's lung and healthy farmers asymptomatic for this condition were exposed to mouldy hay and performed cardiopulmonary exercise testing before and 4 $\mathrm{h}$ after exposure.
* Section for Pulmonary Diseases, Dept of Internal Medicine I, Klinikum Grosshadern, University of Munich, Munich, Germany. **Dept of Internal Medicine II, Charite, Humboldt-University of Berlin, Berlin, Germany.

Correspondence: M. Schwaiblmair Section for Pulmonary Diseases Dept of Internal Medicine I Klinikum Grosshadern

University of Munich

Marchioninistrasse 15 81366 Munich

Germany

Keywords: Acute alveolitis cardiopulmonary exercise testing farmer's lung disease gas exchange

Received: August 221996 Accepted after revision July 101997

\section{Methods}

\section{Study population}

The study included 36 farmers. Group $1(n=21)$ included patients who had experienced episodes of farmer's lung in their medical history and who were in full clinical remission at the time of study. Group $2(n=15)$ consisted of asymptomatic farmers who had not experienced episodes of farmer's lung. The following inclusion criteria, applied pre-exposure, were used to establish the diagnosis of farmer's lung: 1) a clinical history of acute episodes several hours after exposure to mouldy hay; 2) lung function and radiological features consistent with hypersensitivity pneumonitis in the medical history; and 3 ) the demonstration of specific immunoglobulin $G$ (IgG) serum antibodies against Saccharopolyspora rectivirgula, Thermoactinomyces vulgaris or Aspergillus fumigatus $[10,11]$. All three criteria had to be fulfilled. With the exception of one asymptomatic farmer, all of the individuals included in this study were nonsmokers. The atopic status, as evaluated by skin-prick testing with ubiquitous type I allergens, was negative in all individuals tested. From 4 weeks before until the time 
Table 1. - Characteristics of study subjects and lung function parameters before (pre) and the maximum change within the $6 \mathrm{~h}$ period following (post) exposure to mouldy hay

\begin{tabular}{llccc}
\hline & Group 1 & Group 2 & p-value \\
\hline Subjects & & 21 & 15 & \\
Gender F/M & & $6 / 15$ & $5 / 10$ & \\
Age yrs & $49 \pm 12$ & $40 \pm 14$ & NS \\
Height cm & & $171 \pm 7$ & $172 \pm 9$ & NS \\
Weight kg & $76 \pm 14$ & $74 \pm 13$ & NS \\
Specific IgG antibodies & 88 & 87 & NS \\
$\%$ positive & & & & \\
FVC \% pred & pre & $100 \pm 18$ & $104 \pm 16$ & NS \\
& post & $78 \pm 21$ & $104 \pm 15$ & $<0.01$ \\
FEV1/FVC \% & pre & $73 \pm 7$ & $80 \pm 8$ & NS \\
& post & $70 \pm 8$ & $79 \pm 9$ & NS \\
TL,CO \% pred & pre & $100 \pm 19$ & $96 \pm 18$ & NS \\
& post & $85 \pm 20$ & $92 \pm 19$ & NS \\
RV \% pred & pre & $114 \pm 44$ & $98 \pm 33$ & NS \\
& post & $136 \pm 40$ & $105 \pm 29$ & NS \\
TLC \% pred & pre & $100 \pm 18$ & $102 \pm 12$ & NS \\
& post & $97 \pm 23$ & $102 \pm 12$ & NS \\
\hline
\end{tabular}

\$: significance of difference between Group 1 and Group 2 . Data are presented as mean \pm SD. Group 1: patients with farmer's lung disease; Group 2: farmers asymptomatic for farmer's lung disease; FVC: forced vital capacity; FEV1: forced expiratory volume in one second; $T \mathrm{~L}, \mathrm{CO}$ : single-breath transfer factor of the lung for carbon monoxide; RV: residual volume; TLC: total lung capacity; $\%$ pred: percentage of predicted value; ns: nonsignificant; M: male; F: female; IgG: immunoglobulin $\mathrm{G}$.

of the exposure, none of the patients received immunosuppressive therapy. All participants were free of symptoms at the time of exposure and had lung function test results in the normal range. Two farmers in group 1 showed radiological changes consistent with fine pinpoint opacities. Asymptomatic farmers and patients did not differ in anthropometric data (table 1).

\section{Pulmonary function testing}

Pulmonary function tests included forced vital capacity (FVC), total lung capacity (TLC), forced expiratory volume in one second (FEV1) and single-breath carbon monoxide lung transfer factor (TL,CO) (Body Test, Jaeger, Germany). Specific airway resistance (sRaw) was measured by body plethysmography. Quality control procedures and predicted values (\% pred) were applied according to the standards of the European Coal and Steel Community (ECSC) 1993 [12]. Blood gases were analysed at rest and during maximal work capacity using arterialized ear lobe blood (Radiometer ABL500, Copenhagen, Denmark)

\section{Cardiopulmonary exercise testing}

In all individuals, an incrementally progressive, symptom-limited cardiopulmonary exercise test was performed. An electrically-braked cycle ergometer was used (Ergotest; Jaeger, Germany). Cardiac frequency and rhythm were monitored by an electrocardiograph. The participants were connected to a two-way, low-resistance ymouthpiece and a pneumotachograph, and were breathing room air. The expired air was collected continuously in a Douglas bag. $\mathrm{O}_{2}$ and $\mathrm{CO}_{2}$ were analysed every 15 s (Ergopneumotest EOS; Jaeger, Germany). The Ergopneumotest provided recordings of minute ventilation $\left(V^{\prime} \mathrm{E}\right)$, oxygen consumption $\left(V^{\prime} \mathrm{O}_{2}\right)$, carbon dioxide output $\left(V^{\prime} \mathrm{CO}_{2}\right)$ and respiratory exchange ratio (RQ). After 5 min of adaptation to the mouthpiece, the workload $\left(W^{\prime}\right)$ was increased in $30 \mathrm{~W}$ steps every 3 min up to the point of exhaustion (inability to maintain a constant speed and/or to reach $90 \%$ of predicted maximal cardiac frequency and/or intolerable dyspnoea) [13]. Maximum workload $\left(W^{\prime} \max \right)$ was defined as the highest work level reached and maintained for at least $1 \mathrm{~min}$. Similarly, maximum cardiac frequency $\left(f_{c}\right.$, max $)$, maximum oxygen uptake $\left(V^{\prime} \mathrm{O}_{2}, \max \right)$ and maximum ventilation ( $V^{\prime} \mathrm{E}$,max) were defined as the highest levels reached during the test. Maximum voluntary ventilation (MVV) was estimated by multiplying FEV $1 \times 35$ [14]. Simultaneously, physiological dead space/tidal volume $(V \mathrm{D} / V \mathrm{~T})$ was derived from the measured arterial carbon dioxide tension $\left(\mathrm{Pa}_{\mathrm{a}}, \mathrm{CO}_{2}\right)$. The alveolar to arterial oxygen gradient $\left(\mathrm{D}(\mathrm{A}-\mathrm{a}), \mathrm{O}_{2}\right)$ was determined using the simplified alveolar gas equation based on arterial blood gas analysis. Standard exercise testing predicted values were used [13].

\section{Exposure test}

Hay exposure tests were standardized, and were performed as published previously $[1,3,4,11]$. In short, the study participants tossed a mixture of mouldy hay specimens obtained from patients with farmer's lung disease in a designated chamber for $1 \mathrm{~h}$. An observation period of $6 \mathrm{~h}$ followed. During this time, the onset of general symptoms and lung impairment was monitored.

A full set of pulmonary function tests was performed at baseline, followed by measurement of FVC (every hour), TLC (every hour) and TL,CO (1, 3, 5 and $6 \mathrm{~h}$ postexposure) at different time-points. To ensure that these parameters were not affected by a bronchial obstruction, FEV1 and sRaw were determined every hour. For FVC, TLC and TL,CO to be considered for analysis, FEV1 and $\mathrm{s} R$ aw had to be in the normal range. Body temperature was taken before exposure and every hour thereafter. Heparinized blood was drawn before, and 1 and $6 \mathrm{~h}$ after the exposure.

The cardiopulmonary exercise tests were performed in identical fashion before exposure and $4 \mathrm{~h}$ after exposure. Arterial blood gas determinations during rest and exercise were performed with the patient in an upright position and breathing room air.

\section{Statistical analysis}

All data are presented as mean \pm standard deviation (SD). A two sample t-test was used to compare values between the two groups (with Bonferroni post-test correction where appropriate). Within-group analysis was performed using a Mann-Whitney test (with Bonferroni post-test correction where appropriate). A one-way analysis of variance (ANOVA) of the postexposure values, using the pre-exposure values as covariates, was performed. A p-value less than 0.05 was regarded as significant. 


\section{Results}

\section{Systemic and pulmonary reactions}

Following exposure to mouldy hay, all patients with farmer's lung (Group 1) developed general symptoms with chills, myalgias and fatigue. In parallel, a marked rise in body temperature $\left(1.1 \pm 0.2^{\circ} \mathrm{C}\right.$ was recorded, whereas the rise in the group of asymptomatic farmers (Group 2) was significantly less $\left(0.6 \pm 0.2^{\circ} \mathrm{C} ; \mathrm{p}<0.05\right)$. The rising temperature in Group 2 may be caused by the nor-

Table 2. - Cardiopulmonary exercise testing before (pre) and $4 \mathrm{~h}$ after the end of (post) exposure to mouldy hay

\begin{tabular}{llccc}
\hline & & $\begin{array}{c}\text { Group 1 } \\
(\mathrm{n}=21)\end{array}$ & $\begin{array}{c}\text { Group 2 } \\
(\mathrm{n}=15)\end{array}$ & p-value \\
\hline $\mathrm{Pa}_{\mathrm{a}, \mathrm{O}_{2}}$ at rest $\mathrm{kPa}$ & pre & $10.2 \pm 1.2$ & $11.3 \pm 1.2$ & $<0.05$ \\
& post & $8.4 \pm 1.2$ & $10.8 \pm 1.4$ & $<0.001$ \\
${\mathrm{~Pa}, \mathrm{O}_{2}}$ during & pre & $10.1 \pm 2.0$ & $11.6 \pm 1.1$ & $<0.05$ \\
exercise kPa & post & $8.4 \pm 2.5$ & $11.2 \pm 1.3$ & $<0.01$ \\
$W^{\prime} \mathrm{W}$ & pre & $130 \pm 47$ & $126 \pm 45$ & $\mathrm{NS}$ \\
& post & $112 \pm 42$ & $118 \pm 39$ & $\mathrm{NS}$ \\
$V^{\prime} \mathrm{O}_{2} \mathrm{~L} \cdot \mathrm{min}^{-1}$ & pre & $2.1 \pm 0.5$ & $2.0 \pm 0.6$ & $\mathrm{NS}$ \\
& post & $1.8 \pm 0.6$ & $1.8 \pm 0.6$ & $\mathrm{NS}$ \\
$\mathrm{BR} \% \mathrm{MVV}$ & pre & $57 \pm 13$ & $42 \pm 8$ & $<0.01$ \\
& post & $71 \pm 22$ & $41 \pm 9$ & $<0.001$ \\
$V \mathrm{D} / V \mathrm{~T}$ & pre & $0.30 \pm 0.10$ & $0.25 \pm 0.11$ & $\mathrm{NS}$ \\
& post & $0.36 \pm 0.11$ & $0.25 \pm 0.10$ & $<0.05$ \\
$\mathrm{D}(\mathrm{A}-\mathrm{a}), \mathrm{O}_{2} \mathrm{kPa}$ & pre & $6.2 \pm 0.9$ & $4.3 \pm 1.5$ & $<0.05$ \\
& post & $8.0 \pm 1.1$ & $4.7 \pm 1.7$ & $<0.01$ \\
\hline
\end{tabular}

\#: significance of difference between Group 1 and Group 2 . Data are presented as mean \pm SD. Group 1: patients with farmer's lung disease; Group 2: farmers asymptomatic for farmer's lung disease; $\mathrm{Pa}, \mathrm{O}_{2}$ : arterial oxygen tension; $W^{\prime}$ : workrate; $V^{\prime} \mathrm{O}_{2}$ : maximum oxygen uptake; BR: breathing reserve in percentage of the maximum voluntary ventilation (MVV); $V \mathrm{D} /$ $V$ T: physiological dead space/tidal volume during maximum exercise; $\mathrm{D}(\mathrm{A}-\mathrm{a}), \mathrm{O}_{2}$ : alveolar to arterial oxygen difference during maximum exercise. Ns: nonsignificant. mal diurnal temperature fluctuations, since the hay exposure took place between 09.00 and $10.00 \mathrm{~h}$, and the temperature rose in the course of the day. Alternatively, the increased temperature in Group 2 may indicate a minor systemic reaction. The two groups had similar pre-exposure values of FVC, TLC and TL,CO (table 1). During the observation period of $6 \mathrm{~h}$, Group 1 exhibited a remarkable decline in FVC $(100 \pm 18$ to $78 \pm 21 \%$ pred; $\mathrm{p}<0.01)$ and $T \mathrm{~L}, \mathrm{CO}(100 \pm 19$ to $85 \pm 20 \%$ pred; $\mathrm{p}<0.05)$ following exposure. All patients in Group 1 showed a decrease of $\geq 10 \%$ in FVC, and $86 \%$ of symptomatic farmers developed a decrease of $\geq 20 \%$ in FVC. TLC and FEV1 in Group 1 were not impaired by an increased RV after exposure $[15,16]$. In contrast, Group 2 developed no change in FVC, FEV1, TLC and TL,CO.

\section{Cardiopulmonary exercise test}

The symptomatic and asymptomatic groups differed significantly in arterial oxygen tension $\left(\mathrm{Pa}_{\mathrm{a}} \mathrm{O}_{2}\right)$ at rest. During the pre-exposure exercise test, the $\mathrm{Pa}, \mathrm{O}_{2}$ did not decrease in either group. Following exposure, Group 1 showed a significant decrease in $\mathrm{Pa}_{\mathrm{a}} \mathrm{O}_{2}$ at rest and during maximal exercise, whereas Group 2 showed values similar to those before exposure (table 2).

The participants in both groups provided the same workrate before exposure. Four hours after exposure, all individuals studied developed a minor, but not significant, loss of work capacity. Neither group differed in the $V^{\prime} \mathrm{O}_{2}$, max before and after exposure and reached a mean $V^{\prime} \mathrm{O}_{2}$ value of $83-99 \%$ pred (table 2).

Major differences in $\mathrm{D}(\mathrm{A}-\mathrm{a}), \mathrm{O}_{2}, V \mathrm{D} / V_{\mathrm{T}}$ and breathing reserve during maximum effort were detectable between the two groups (table 3 ). There was also a significant difference in $\mathrm{D}(\mathrm{A}-\mathrm{a}), \mathrm{O}_{2}$ before exposure (Group 1 vs Group $26.2 \pm 0.9$ vs $4.3 \pm 1.5 \mathrm{kPa}$, respectively; $\mathrm{p}<0.05)$; the difference increased further $4 \mathrm{~h}$ postexposure $(8.0 \pm 1.1 \mathrm{vs}$ $4.7 \pm 1.7 \mathrm{kPa}$, respectively; $\mathrm{p}<0.01)$. Eight of the 21 individuals in Group 1 (versus two of the 15 individuals in

Table 3. - Univariate analysis of postexposure (post) values for pulmonary function and cardiopulmonary exercise test parameters for the two groups, using the pre-exposure values (pre) as covariates

\begin{tabular}{|c|c|c|c|c|c|}
\hline \multicolumn{2}{|l|}{ Parameters } & \multicolumn{2}{|c|}{$\Delta$ pre/post $\%$} & \multirow{2}{*}{$\frac{\mathrm{p} \text {-value } \neq}{<0.05}$} & \multirow{2}{*}{$\frac{95 \% \text { CI }}{60.3-95.7}$} \\
\hline FVC \% pred & Group 1 & -21.6 & $(-22)$ & & \\
\hline & Group 2 & -0.7 & $( \pm 0)$ & NS & $94.9-112.3$ \\
\hline \multirow[t]{2}{*}{ FEV1/FVC $\%$ pred } & Group 1 & -2.1 & $(-3)$ & NS & $61.8-79.2$ \\
\hline & Group 2 & -0.5 & $(-1)$ & NS & $74.2-84.1$ \\
\hline \multirow[t]{2}{*}{ TL,CO $\%$ pred } & Group 1 & -15.1 & $(-15)$ & $<0.05$ & $60.4-110.1$ \\
\hline & Group 2 & -3.1 & $(-3)$ & NS & $81.7-103.3$ \\
\hline \multirow[t]{2}{*}{ TLC $\%$ pred } & Group 1 & -1.5 & $(-1)$ & NS & $77.9-116.8$ \\
\hline & Group 2 & +0.3 & $( \pm 0)$ & NS & $94.7-109.1$ \\
\hline \multirow[t]{2}{*}{$W^{\prime} \quad \mathrm{W}$} & Group 1 & -17.5 & $(-13)$ & NS & $77.7-147.3$ \\
\hline & Group 2 & -8.1 & $(-6)$ & NS & $95.2-140.5$ \\
\hline \multirow[t]{2}{*}{$V^{\prime} \mathrm{O}_{2} \quad \mathrm{~L} \cdot \mathrm{min}^{-1}$} & Group 1 & -0.25 & $(-12)$ & NS & $1.34-2.34$ \\
\hline & Group 2 & -0.12 & $(-6)$ & NS & $1.50-2.18$ \\
\hline \multirow[t]{2}{*}{$\mathrm{BR} \% \mathrm{MVV}$} & Group 1 & +13.8 & $(+24)$ & $<0.01$ & $52.2-89.0$ \\
\hline & Group 2 & -0.5 & $(-1)$ & NS & $36.5-46.4$ \\
\hline \multirow{2}{*}{$V \mathrm{D} / V \mathrm{~T}$} & Group 1 & +0.06 & $(+20)$ & NS & $0.26-0.45$ \\
\hline & Group 2 & \pm 0.0 & $( \pm 0)$ & NS & $0.19-0.30$ \\
\hline \multirow[t]{2}{*}{$\mathrm{D}(\mathrm{A}-\mathrm{a}), \mathrm{O}_{2} \mathrm{kPa}$} & Group 1 & +1.85 & $(+30)$ & $<0.01$ & $5.41-10.58$ \\
\hline & Group 2 & +0.45 & $(+11)$ & NS & $3.74-5.71$ \\
\hline
\end{tabular}

$\$$ : within group significance. Data are presented as difference $(\Delta)$ between pre- and postexposure, with percentage in parenthesis, and a $95 \%$ confidence interval $(95 \% \mathrm{CI})$ for postexposure values. For definitions see legends to table 1 and 2. 
Group 2) had a pathological $\mathrm{D}(\mathrm{A}-\mathrm{a}), \mathrm{O}_{2}$ during exercise before the exposure test. All Group 1 individuals showed a pathological $\mathrm{D}(\mathrm{A}-\mathrm{a}), \mathrm{O}_{2}$ during exercise in the postexposure test. Six asymptomatic farmers (40\% of Group 2) also showed a widening of $\mathrm{D}(\mathrm{A}-\mathrm{a}), \mathrm{O}_{2}$ during exercise postexposure $(5.3-7.9 \mathrm{kPa})$, although the decrease in $\mathrm{Pa}, \mathrm{O}_{2}$ did not exceed $1.1 \mathrm{kPa}$ compared to the pre-exposure value. Before exposure, the two groups had similar values for $V \mathrm{D} / V \mathrm{~T}$. Postexposure $V \mathrm{D} / V \mathrm{~T}$ in patients with farmer's lung was increased (Group 1 vs Group 2 $0.36 \pm 0.04$ vs $0.25 \pm 0.03$, respectively; $\mathrm{p}<0.05$ ). Additionally, Group 1 showed a diminished breathing reserve before exposure (Group 1 vs Group $257 \pm 5$ vs $42 \pm 2 \%$ of MVV, respectively; $\mathrm{p}<0.01$ ); and even more pronounced after exposure $(71 \pm 8$ vs $41 \pm 2 \%$ of MVV, respectively; $\mathrm{p}<0.001)$.

\section{Discussion}

Our study demonstrates that, following exposure to mouldy hay, patients with a history of farmer's lung show an increased $\mathrm{D}(\mathrm{A}-\mathrm{a}), \mathrm{O}_{2}$ and $V \mathrm{D} / V \mathrm{~T}$ during exercise. In addition, a ventilation-perfusion mismatch developed. Furthermore, patients with episodes of farmer's lung had a decreased breathing reserve and a greater $\mathrm{D}(\mathrm{A}$ a), $\mathrm{O}_{2}$ at baseline. Finally, a considerable number of asymptomatic farmers demonstrated a pathological increase of $\mathrm{D}(\mathrm{A}-\mathrm{a}), \mathrm{O}_{2}$ during exercise after exposure.

In some cases of suspected hypersensitivity pneumonitis, an inhalation provocation test is performed to secure the diagnosis. At present, there are no generally accepted criteria that define a positive "alveolar" response induced by exposure [17]. The characteristic findings that may be expected in association with positive alveolar reactions are a restrictive ventilatory defect and a decreased transfer factor, but both ventilation and transfer factor may remain apparently unchanged [15, 1820]. In the study by HENDRICK et al. [20], measurement of minute ventilation during exercise proved to be the most useful parameter, having a sensitivity of $85 \%$.

It is generally thought that lung fibrosis is preceded by an alveolitis, i.e. an infiltration of the alveoli and interstitium with inflammatory cells [3, 21-27]. Under such circumstances, the alveoli are filled with substrates which reduce the diffusing capacity for $\mathrm{O}_{2}$. In the present study, patients with farmer's lung developed considerable changes in $\mathrm{D}(\mathrm{A}-\mathrm{a}), \mathrm{O}_{2}$ following exposure to hay dust, i.e. after induction of an acute alveolitis. Several studies have indicated that ventilation-perfusion mismatch and shunt are responsible for most of the increased $\mathrm{D}(\mathrm{A}-\mathrm{a}), \mathrm{O}_{2}$ during exercise [28-31]. As the perfusion rate during exercise increases in the lung units with inflammatory cell infiltrates, $\mathrm{O}_{2}$ in the gas space can no longer equilibrate with $\mathrm{O}_{2}$ in the red cell. Thus, hypoxaemia becomes more pronounced as the blood flow increases. In addition a ventilation-perfusion mismatch ensues with the consequence of an increased $\mathrm{D}(\mathrm{A}-\mathrm{a}), \mathrm{O}_{2}$.

Diffusion limitation and low mixed venous oxygen tension also significantly contribute to this enlarged gradient. There is controversy regarding the relative importance of diffusion limitation in the widened alveolar-arterial gradient [28-31]. In the present study, we observed a reduced $T \mathrm{~L}, \mathrm{CO}$ in patients with farmer's lung postexposure, but there was no significant difference in TL,CO between the two groups postexposure. However, the pathological $\mathrm{D}(\mathrm{A}-\mathrm{a}), \mathrm{O}_{2}$ is not followed by a significant decrease of $\mathrm{TL}, \mathrm{CO}$; the measurement of diffusing capacity at rest is unable to detect early pulmonary damage. Forty per cent of asymptomatic farmers had a marked increase of $\mathrm{D}(\mathrm{A}-\mathrm{a}), \mathrm{O}_{2}$ during exercise. This apparent discordance may reflect the observation that increased $\mathrm{D}$ (Aa), $\mathrm{O}_{2}$ during exercise is caused mainly by a mismatch of alveolar ventilation and perfusion.

The $\mathrm{D}(\mathrm{A}-\mathrm{a}), \mathrm{O}_{2}$ progressively increases with exercise, reaching values of $2.7 \pm 4.0 \mathrm{kPa}$ during maximal exercise in normal individuals $[32,33]$. In the study by HANSEN and WASSERMAN [33] of 77 normal and healthy active males, $\mathrm{D}(\mathrm{A}-\mathrm{a}), \mathrm{O}_{2}$ values of $1.7 \mathrm{kPa}$ at rest and 2.6 $\mathrm{kPa}$ during maximum exercise were found. During maximum exercise, $\mathrm{D}(\mathrm{A}-\mathrm{a}), \mathrm{O}_{2}$ was greater than $4.7 \mathrm{kPa}$ in only 3 of the 77 males (4\%). In the present study, $40 \%$ of the asymptomatic farmers showed a pathological increase of $\mathrm{D}(\mathrm{A}-\mathrm{a}), \mathrm{O}_{2}>4.7 \mathrm{kPa}$ after exposure. This observation may be caused by a variety of factors, including $\mathrm{O}_{2}$ diffusion limitation, ventilation/perfusion $\left(V^{\prime} / Q^{\prime}\right)$ mismatching and reduction in mixed venous $\mathrm{O}_{2}$ [32]. In patients with an interstitial lung disease $V^{\prime} / Q^{\prime}$ mismatching remains by far the most important contributor to the total $\mathrm{D}(\mathrm{A}-\mathrm{a}), \mathrm{O}_{2}$, although diffusion limitation may develop during exercise [32]. Thus, $V^{\prime} / Q^{\prime}$ inequality as indicated by an elevated $\mathrm{D}(\mathrm{A}-\mathrm{a}), \mathrm{O}_{2}$ may signify individuals at risk for developing a clinical form of hypersensitivity pneumonitis.

In addition to the widened $\mathrm{D}(\mathrm{A}-\mathrm{a}), \mathrm{O}_{2}$, we observed an increased $V \mathrm{D} / V \mathrm{~T}$ during exercise in patients with farmer's lung. KeOGH and CRYstal [21] suggested that measurement of gas exchange during exercise is the most sensitive test for the detection of functional impairment in patients with alveolitis, whereas transfer factor and arterial blood gas tension at rest bear little or no relation to the extent of the disease. This suggestion is based on study results showing that lung volumes roughly parallel the severity of lung fibrosis but bear no relation to the extent of alveolitis [21]. Compared to the asymptomatic farmers, before exposure the patients provided no changes in conventional lung function parameters but an increase in $V \mathrm{D} / V \mathrm{~T}$. This may reflect an inefficient ventilation pattern, and is one of the major factors responsible for the increased ventilatory requirement [31]. $V \mathrm{D} / V \mathrm{~T}$ depends on the pattern of breathing and values $>0.3$ indicate the presence of abnormal alveolar dead space, high ventilation/perfusion units and maldistribution of blood flow $[34,35]$. Since the maximum breathing frequency is not significantly different between the two groups, we believe that the influence of $V^{\prime} / Q^{\prime}$ inhomogeneity within the lungs is important, possibly based on inflammatory processes at the alveolar level [11]. Our finding suggest a latent $V^{\prime} / Q^{\prime}$ mismatch in symptomatic farmers even before exposure to mouldy hay. When the proportion of high $V^{\prime} / Q^{\prime}$ units within the lung increases, $V^{\prime} \mathrm{E}$ increases to maintain $P \mathrm{a}, \mathrm{CO}_{2}$. The increase in $V^{\prime} \mathrm{E}$, however, is often inadequate to compensate for the increased $V \mathrm{D} / V \mathrm{~T}$.

Additionally, our patients with farmer's lung demonstrated a difference concerning the breathing reserve pre- and postexposure, whereas asymptomatic farmers did not. Patients with significant lung fibrosis often display higher levels of $V^{\prime} \mathrm{E}$ during exercise than normal 
subjects [28, 38]. The observed reduced breathing reserve is one of the criteria often used to establish ventilatory limitation during exercise [10]. This is largely due to increased $V \mathrm{D} / V \mathrm{~T}$, but other factors, such as input from mechanoreceptors, hypoxaemia, exhausted respiratory muscles and mediators of inflammation, may contribute $[28,36-40]$. In view of the multiple mechanisms likely to be involved in ventilatory responses observed during exercise in interstitial lung disease, the reasons for this merit additional studies. Although pulmonary vasculitis has been reported in some biopsy specimens obtained very early during farmer's lung, it has not been present in the vast majority of cases [22].

In the present study, concerning acute alveolitis induced by mouldy hay exposure, $\mathrm{D}(\mathrm{A}-\mathrm{a}), \mathrm{O}_{2}$ and $V \mathrm{D} / V_{\mathrm{T}}$ were clearly different between the two groups, whereas lung function parameters, such as TLC and TL,CO, did not differ significantly between pre- and postexposure. Thus, it is possible that $\mathrm{D}(\mathrm{A}-\mathrm{a}), \mathrm{O}_{2}$ and $V \mathrm{D} / V \mathrm{~T}$ reflect the changes in gas exchange induced by an acute alveolitis more accurately than standard lung function parameters. It is noteworthy that in a study, comparing data immediately before and after exercise, which revealed greater $V^{\prime} / Q^{\prime}$ inequality on exercise, no spirometric abnormalities could be demonstrated [28, 32]. Since the magnitude of $\mathrm{D}(\mathrm{A}-\mathrm{a}), \mathrm{O}_{2}$ during exercise cannot be predicted either from transfer factor or all resting variables in a multilinear regression equation, cardiopulmonary exercise testing is an important addition to the evaluation of disease severity $[8,40]$. Moreover, using cardiopulmonary exercise testing may make it possible to identify individuals with hypersensitivity pneumonitis at a very early stage of the disease. Our findings are similar to those of PAPPAS and NEWMAN [41] in a report on beryllium disease, and to those of MiLLER et al. [42] in sarcoidosis patients. We are aware of the potential limitations of the present investigation, including the small numbers of individuals tested and possible influences of confounding factors, such as coexisting lung disease. Nevertheless, we observed remarkable changes in gas exchange and exercise parameters following antigen exposure.

In conclusion, our study showed significant changes in pulmonary gas exchange during exercise in this model of acute hypersensitivity pneumonitis. This would suggest that, in cases of suspected hypersensitivity pneumonitis, cardiopulmonary exercise testing could be a clinically meaningful procedure, in the routine programme as well as during an exposure test. For the definition of clear cut values that are diagnostic for an acute episode of hypersensitivity pneumonitis, further studies with greater sample sizes are mandatory. Asymptomatic farmers with an increased alveolar to arterial difference in oxygen tension during exercise postexposure should be monitored closely.

\section{References}

1. Richerson H, Bernstein L, Fink J, et al. Guidelines for the clinical evaluation of hypersensitivity pneumonitis. J Allergy Clin Immunol 1989; 84: 839-844.

2. Reyes C, Wenzel F, Lawton B, Emanuel D. The pulmonary pathology of farmer's lung disease. Chest 1982; 81: 142-146.
3. Salvaggio J. Hypersensitivity pneumonitis. J Allergy Clin Immunol 1987; 79: 558-571.

4. Hendrick D, Marshall R, Faux J, Krall J. Positive "alveolar" responses to antigen inhalation provocation tests: their validity and recognition. Thorax 1980; 35: 415-427.

5. Chinet T, Jaubert F, Dusser D, Danel C, Chretien J, Huchon G. Effects of inflammation and fibrosis on pulmonary function in diffuse lung fibrosis. Thorax 1990; 45: 675678.

6. Newman L, Bobka C, Schumacher B, et al. Compartmentalized immune response reflects clinical severity of beryllium disease. Am J Respir Crit Care Med 1994; 150: 135-142.

7. Bradvik I, Wollmer P, Blom-Bulow B. Lung mechanics and gas exchange during exercise in pulmonary sarcoidosis. Chest 1991; 99: 572-578.

8. Risk C, Epler G, Gaensler E. Exercise alveolar-arterial oxygen pressure difference in interstitial lung disease. Chest 1984; 85: 69-74.

9. Amishima M, Munakata M, Ohtsuka Y, et al. Dairy farmers have increased methacholine bronchial responsiveness indepent of sensitization to mold antigens. Am J Respir Crit Care Med 1995; 151: 1794-1798.

10. Hansen J, Wasserman K. Pathophysiology of activity limitation in patients with interstitial lung disease. Chest 1996; 109: 1566-1575.

11. Vogelmeier C, Krombach F, Münzing S, et al. Activation of blood neutrophils in acute episodes of farmer's lung. Am Rev Respir Dis 1993; 148: 396-400.

12. Quanjer PhH, Tammeling GJ, Cotes JE, Pedersen OF, Peslin R, Yernault J-C. Lung volumes and forced ventilatory flows. Report Working Party "Standardization of Lung Function Tests". European Coal and Steel Community. Eur Respir J 1993; 6 (Suppl. 16): 5-40.

13. Wasserman K, Hansen J, Sue D, Whipp B, Casaburi R. In: Principles of Exercise Testing and Interpretation. Philadelphia, Lea \& Febriger, 1994; pp. 1-97.

14. Marciniuk D, Gallgher C. Clinical exercise testing in interstitial lung disease. Clin Chest Med 1994; 15: 287-303.

15. Warren C, Tse K, Cherniack R. Mechanical properties of the lungs in extrinsic allergic alveolitis. Thorax 1978; 33: 315-321.

16. Harries M, Heard B, Geddes D. Extrinsic allergic bronchiolitis in a bird fancier. Br J Ind Med 1984; 41: 220223.

17. Parkes R. In: Occupational Lung Disorders. London, Butterworth-Heinemann, 1995; pp. 46-58.

18. Hargreave F, Pepys J. Allergic respiratory reactions in bird fanciers provoked by allergen inhalation provocation tests. relation to clinical features and allergic mechanism. J Allergy Clin Immunol 1972; 50: 157-173.

19. Williams J. Inhalation and skin tests with extracts of hay and fungi in patients with farmer's lung. Thorax 1963; 18: 182-196.

20. Hendrick D, Marshall R, Faux J, Krall J. Positive "alveolar" responses to antigen inhalation provocation tests: their validity and recognition. Thorax 1980; 35: 415-427.

21. Keogh B, Crystal R. Clinical significance of pulmonary function tests. Pulmonary function testing in interstitial pulmonary disease: what does it tell us? Chest 1980; 78: 856-865.

22. Costabel U. The alveolitis of hypersensitivity pneumonitis. Eur Respir J 1988; 1: 5-9.

23. Fournier E, Tonnel A, Gosset P, Wallaert B, Ameisen $\mathrm{J}$, Voisin C. Early neutrophil alveolitis after inhalation challenge in hypersensitivity pneumonitis. Chest 1985; 88: 563-566. 
24. Ghose T, Landrigan P, Killeen R. Immunopathological studies in patients with farmer's lung. Clin Allergy 1974; 4: 119-129.

25. Crystal R, Bittermann P, Rennard S, Hance A, Keogh B. Interstitial lung disease of unknown cause: disorders characterized by chronic inflammation of the lower respiratory tract. $N$ Engl J Med 1984; 310: 154-166 and 235-244.

26. Hunninghake G, Garrett K, Richerson H, et al. Pathogenesis of the granulomatous lung disease. Am Rev Respir Dis 1984; 130: 476-496.

27. Mohsenifar Z, Brown H, Koerner S. Effect of breathing pattern on dead space ventilation $(V \mathrm{~d} / V \mathrm{t})$ during exercise. Respiration 1985; 47: 232-236.

28. Agusti A, Roca J, Gea J, Wagner P, Xaubet A, RodriguezRoisin R. Mechanisms of gas exchange impairment in idiopathic pulmonary fibrosis. Am Rev Respir Dis 1991; 143: 219-225.

29. Jernudd-Wilhelmsson Y, Hornblad Y, Hedenstierna G. Ventilation-perfusion relationships in interstitial lung disease. Eur J Respir Dis 1986; 68: 39-49.

30. Hempleman R, Hughes J. Estimating exercise DI, $\mathrm{O}_{2}$ and diffusion limitation in patients with interstitial fibrosis. Respir Physiol 1991; 83: 167-178.

31. Hughes J, Lockwood D, Jones H. $D$ L, CO/ $Q^{\prime}$ and diffusion limitation at rest and on exercise in patients with interstitial fibrosis. Respir Physiol 1991; 83: 155-166.

32. Wagner P. Ventilation-perfusion matching during exercise. Chest 1992; 101: 192S-198S.

33. Hansen J, Sue D, Wasserman K. Predicted values for clinical exercise testing. Am Rev Respir Dis 1984; 129: S49-S55.

34. Harris E, Hunter M, Seelye E, Vedder M, Whitlock R. Prediction of the physiologic dead space in resting normal subjects. Clin Sci Mol Med 1973; 45: 375-381.

35. Weisman I, Zeballos J. An integrated approach to the interpretation of cardiopulmonary exercise testing. Clin Chest Med 1994; 15: 421-445.

36. Gaensler E, Carrington C. Open biopsy for chronic diffuse infiltrative lung disease: clinical, roentgenographic and physiologic correlations in 502 patients. Ann Thorac Surg 1980; 30: 411-426.

37. Javaheri S, Sicilian L. Lung function, breathing pattern and gas exchange in interstitial lung disease. Thorax 1992; 47: 93-97.

38. Spiro S, Dowdeswell I, Clark T. An analysis of submaximal exercise responses in patients with sarcoidosis and fibrosing alveolitis. Br J Dis Chest 1981; 75: 169-176.

39. Burdon J, Killian K, Jones N. Pattern of breathing during exercise in patients with interstitial lung disease. Thorax 1983; 38: 778-784.

40. Schwaiblmair M, Behr J, Fruhmann G. Cardiorespiratory responses to incremental exercise in patients with systemic sclerosis. Chest 1996; 110: 1520-1525.

41. Pappas G, Newman L. Early pulmonary physiologic abnormalities in beryllium disease. Am Rev Respir Dis 1993; 148: 661-666.

42. Miller A, Brown L, Sloane M. Cardiorespiratory responses to incremental exercise in sarcoidosis patients with normal spirometry. Chest 1995; 107: 323-329. 